\title{
Información, incertidumbre y memoria: perpetradores en la estrategia de los atentados de Al-Qaeda e ISIS
}

\author{
Professor Luis VERES, PhD \\ Facultad de Filología \\ Universidad de Valencia, Spain \\ E-mail: casa281068@yahoo.es
}

\begin{abstract}
One of the extreme situations to which the journalistic information has been given since the 19th century is the coverage of terrorist attacks. The last decade is marked by the attacks derived from the conflict in Syria and the acquisition of part of the territory of Iraq and Syria by the self-styled Islamic State. This situation has favored the strategy of a war against some Western countries based on surprise and the consequent uncertainty caused by attacks that are difficult to foresee and practically impossible to avoid. The information of these attacks, as in the cases of Nice, Paris, London, involves challenging the media by putting them in a situation where the lack of images, rapid judgments and accelerated information are presented as the only way to inform. This work tries to reflect on this scenario that gives rise to a new mode of informative representation.
\end{abstract}

Keywords: ISIS; Al-Qaeda; Terrorism; Islamism; Communication; Efficiency.

Resumen. Una de las situaciones límite a las que la información periodística se ha dado desde el S.XIX es la cobertura de atentados terroristas. La última década viene marcada por los atentados derivados del conflicto en Siria y la adquisición de parte del territorio de Iraq y Siria por el autodenominado Estado Islámico. Esta situación ha propiciado la estrategia de una guerra contra algunos países de occidente fundamentada en la sorpresa y la consiguiente incertidumbre que causan atentados difícilmente previsibles y prácticamente imposibles de evitar. La información de estos atentados, como en los casos de Niza, París, Londres supone 
retar a los medios al ponerlos en una situación en donde la falta de imágenes, los juicios rápidos y la información acelerada se presentan como la única forma de informar. Este trabajo trata de reflexionar sobre este escenario que da lugar a un nuevo modo de representación informativa.

Palabras clave: ISIS, Al-Qaeda, terrorismo, islamismo, comunicación, eficacia.

\section{Introducción}

La historia del terrorismo viene plagada de ejemplos en los que este fenómeno ha jugado con la idea de incertidumbre utilizando los medios de comunicación como plataforma o altavoz para los contenidos que los distintos grupos terroristas han intentado trasmitir a la opinión pública (Rodrigo, 1999; Veres, 2004aํ)1. Desde la secta de los Haxasin, en Palestina en el S.XI, a los anarquistas del S.XIX; desde los atentados del hotel King David en Israel en 1947, con el cual se logró la independencia de Israel, a los atentados de Munich en 1972, con 4000 cámaras de televisión en los juegos olímpicos para cubrir el secuestro de la delegación israelí, queda claro que el terrorismo siempre ha buscado su presencia en los medios como recurso para lograr el eco propagandístico ansiado. Existe en la naturaleza del terrorismo un deseo de efecto inmediato y también un deseo de perdurabilidad para la causa en la memoria de los hechos. El terrorismo parece desear la perpetuación en el recuerdo de la violencia como forma posible de venganza y como medio de subversión contra su rival. El 11 de septiembre no fue motivado para que murieran 3000 personas en el World Trade Center, sino para que fuera retrasmitido en directo por las televisiones de todo el mundo y cristalizar una imagen en nuestra memoria. Es más, para convertirse en un antes y un después al que se debía enganchar la historia y para forjar un icono que forma parta de la historia del S.XXI y de la memoria de la humanidad.

Pero, lo cierto es que esta simbiosis mediática se ha trasformado notablemente en los últimos años con la proclamación del Estado Islámico y el desarrollo y declive posterior del ISIS o DAESH. Parece que el terrorismo busque nuevas formas comunicativas con el fin de adecuarse a los tiempos y con el fin de conseguir la mayor eficacia comunicativa y así perdurar en mayor medida en la memoria histórica. En primer lugar porque se ha desarrollado un terrorismo acorde a los tiempos de la globalización que ha entrado a formar parte de lo que Ulrich Beck (2002) ha denominado la sociedad de riesgo global, un mundo basado en peligros

1 Este trabajo forma parte del proyecto "Representaciones contemporáneas del perpetrador de violencias de masas: conceptos, relatos e imágenes@ dirigido por Vicente Sánchez-Biosca y Anacleto Ferrer financiado por el Ministerio de Ciencia y Tecnología. HAR2017-83519-P B 
étnicos o nacionalistas que se entremezclan con la pobreza desde el final de la II Guerra Mundial y que han conducido a un uso imperialista de los recursos naturales y el medio ambiente. Todo ello viene dado en un universo en donde se han acabado las fronteras tradicionales y el poder de los estados a la manera clásica. En realidad Internet ha facilitado el desplazamiento de la información, y cualquier persona, con un teléfono móvil, es testigo de una información y creador de esa información. A la vez hay bofetadas por hacerse con el mercado de la comunicación y por conseguir clientes en un mundo en que los móviles están presentes en los cinco continentes. Estas circunstancias contribuyen a incluir los contenidos de los atentados del DAESH, sean de mayor o menor envergadura, porque del calibre del suceso dependerá la cobertura informativa que reciban. Todo ello ha afectado al registro de las masacres, a su difusión y su perdurabilidad en la memoria. Se ha ganado en eficacia comunicativa, mediante el contenido del mensaje, el código y el canal.

Se suele decir que ese nuevo terrorismo islamista nace con Al-Qaeda y el 11 de Septiembre de 2001 a partir de los atentados en Nueva York y Washington, pero lo cierto es que Yihad Islámica y Al-Qaeda ya habían cambiado las cosas mucho antes. Con los atentados de Madrid en 2003, se difundió el mensaje, interesado desde el punto de vista electoral, de que la razón de los atentados era la participación de España en la guerra de Iraq, auspiciada por los Estados Unidos, tras los atentados de Nueva York y Washington. No obstante, Al-Qaeda ya había amenazado a Occidente y, concretamente a España, en una ensoñadora reclamación de Al-Andalus. Ya el 12 de abril de 1985 se había producido un atentado con explosivos en el restaurante El descanso de Madrid, frecuentado por militares norteamericanos. Se saldó con 18 muertos y ochenta heridos, y se responsabilizó a la Yihad Islámica. En 2003 se intensificó esa amenaza, sobre todo a partir de los atentados contra la Casa de España en Casablanca en 2003. Se iniciaba así una nueva oleada de terrorismo que culminaría en los atentados de Atocha el 11 de marzo de 2004, en cuyas bombas se introdujo metralla con el fin de realizar el mayor daño posible. Pero mucho antes, ya en 1998, Al-Qaeda había promovido la creación del Frente para la Guerra Santa contra Cruzados y Judíos con el fin de aunar diversos grupos islamistas desperdigados por Oriente Medio y Asia.

"Al-Qaeda puede haber sido debilitada tras el desmantelamiento de su santuario en territorio afgano y la persecución de que sus miembros han sido objeto en todo el mundo. Pero su estructura terrorista ha revelado su movilidad y flexibilidad, además de haber se descentralizado. Ha conseguido adaptarse a circunstancias adversas, haciéndose entretanto especialmente peligrosa. No va a ser un problema pasajero. Incluso es muy verosímil que, siguiendo la estela de la inacabable crisis palestina, acontecimientos como los de Iraq, sin ser los únicos, pero siendo indudablemente los de mayor trascendencia, estén facilitando la reconstitución de 
Al-Qaeda, permitiendo su propia expansión a la de sus entidades afiliadas, e incluso fortaleciendo sus bases de apoyo social a lo largo y ancho del mundo árabe e islámico, así como ocurre entre sectores propicios de las diásporas musulmanas asentadas en países occidentales." (Reinares, Elorza, 2004, p. 11).

Había surgido un nuevo terrorismo capaz de atentar en cualquier lado del Planeta, con una paciencia y una capacidad de organización que no se había visto antes (Gunaratna en Reinares, Elorza, 2004, p. 78). Se trataba de un terrorismo de alcance global, capaz de planear un atentado durante años, sin prisas, con pleno dominio de las nuevas tecnologías de la información; un terrorismo que reivindicaba la expansión del Islam según el rigorismo salafista, impulsado desde Arabia Saudí, y que, paradójicamente, se volvía en contra de su principal aliado: Estados Unidos, como señalaba el mismo Bin Laden en 1996:

"La orden de matar a los americanos y sus aliados, civiles o militares, es una obligación individual para todo musulmán, que puede hacerlo en cualquier país donde le sea posible, a fin de liberar la mezquita de Al Aqsa y al mezquita santa de sus garras, y para que sus ejércitos salgan de todas las tierras del Islam, derrotados e incapaces de amenazar a ningún musulmán." (Reinares, 2004 en Reinares, Elorza, 2004, p. 22).

\section{El nuevo terrorismo, los nuevos perpetradores y la eficacia comunicativa}

Este nuevo terrorismo ofrece una notable diferencia: el hecho de que a los perpetradores de los atentados no les importa morir en su ejecución. A pesar del idealismo que supone la causa terrorista, nunca en la historia se había dado esta circunstancia, solamente presente en algunos de los primeros atentados de corte anarquista. Y ello supone vincular el terrorismo al Islam, a una visión radical del Islam que implica la muerte en la yihad, un hecho glorioso que conduce a otra vida en medio de un harén de 72 vírgenes en donde el muyahidin disfrutará de placeres inefables durante toda la eternidad. Otra notable diferencia de este terrorismo viene dado por el hecho de que Al-Qaeda sirvió de oposición a la Unión Soviética en el conflicto afgano y esa estructura resultante fue utilizada posteriormente. Se desarrolló una red con células durmientes pero activas en más de cuarenta países y en sociedades donde la población musulmana era abundante, como Francia, España o Reino Unido, adquiriendo la forma de una estructura difusa y difícil de localizar. Hay quien lo relaciona con la postmodernidad o con los videojuegos, una estructura rizomática capaz de extenderse desde Mindanao, en Filipinas, a Yemen, pasando por Iraq, Francia, Reino Unido, España o los Estados Unidos (Žižek, 2006, p. 46).

Como señala Bruce Hoffman, Al-Qaeda ha tenido el acierto estratégico de desarrollarse dentro y fuera del mundo islámico mediante una estructura rizomática capaz de aparecer y desaparecer en un territorio, capaz de trasladarse de un continente a otro. Ha seguido una estructura vertebrada en múltiples frentes en medio 
del internacionalismo, la interculturalidad y la globalización, en medio de aeropuertos donde se extreman las medidas de seguridad ante masas de seres de todas las razas y de todas las nacionalidades. Al-Qaeda e ISIS mantienen una estrategia transnacional y cambiante en donde sus mutaciones se presentan de atentado en atentado.

“Lo que parece claro es que las más sobresalientes amenazas terroristas de hoy en día no provienen necesariamente de una sola fuente, de una organización individual conocida como Al-Qaeda, sino de una multiplicidad de más pequeñas y replicantes Al-Qaedas. En otras palabras, el desafío al que nos enfrentamos ahora no proviene sólo de un numeroso enemigo singular, identificable y localizable geográficamente tal y como era Al-Qaeda en los momentos inmediatamente anteriores al 11-S, sino de una variedad de adversarios más pequeños, con idéntica ideología y orientados a fines similares." (Hoffman en Reinares, Elorza, 2004, p. 124).

Al-Qaeda ha conseguido trasformar la forma de viajar, incluso la sensibilidad y la percepción de los europeos. Al-Qaeda, seguida del ISIS, ha logrado extender la significación del terror y la percepción de inseguridad de los ciudadanos globales. Y las encuestas corroboran esta sensación. Un porcentaje amplio de ciudadanos temen la realización de un atentado en su país. Algunas cifras ponen de relieve estos hechos: el 76\% de los habitantes del Reino Unido y de España lo temían; el $62 \%$ de los italianos, el 52\% de los alemanes y el 51\% de los franceses (Reinares en Reinares, Elorza, 2004, p. 27). Estos datos, sin duda, se han incrementado después de los atentados de Charlie Hebdo y de la sala Bataclán en París, los atentados junto al parlamento de Londres o los atentados de las Ramblas de Barcelona y otros escenarios como Alemania, Túnez, Turquía, Bélgica o Estados Unidos. Al-Qaeda, y sobre todo ISIS, han logrado que el $82 \%$ de las noticias publicadas sobre el Islam sean negativas. Pero lo cierto es que sólo en 2015 ha habido 217 detenidos pos extremismo yihadista en España ${ }^{2}$ y 360000 eventos yihadistas han sido cancelados en Twiter.

\section{La nueva comunicación: la Red y el vídeo}

En toda esta evolución del terrorismo, la comunicación ha evolucionado notablemente como consecuencia de la evolución de los propios medios pero también como un perfeccionamiento de las técnicas y de los sujetos empleados para ello. Se ha sofisticado una vieja técnica con nuevos medios en un nuevo escenario global. Los nuevos perpetradores del terrorismo islamista han cambiado su perfil, jóvenes de segunda o tercera generación que se suman a actuar en Siria o en Europa o en

2 “Tres detenidos en Madrid por terrorismo yihadista, en Expansión, 21-6-2017.www.expan sion.com/economia/politica/2017/06/21/594a07cde5fdea352a8b469c.html. Consultado el 10 de enero de 2017. 
Estados Unidos. Son hijos o nietos de inmigrantes que han visto las dificultades que han padecido sus padres. Son franceses, españoles, belgas o británicos, pero nos e sienten como tales ya que no se ha logrado su integración cultural. Muchos de ellos no tienen formación islámica pero se sienten reconfortados en su vieja cultura: de los miembros de Al-Qaeda dos terceras partes eran laicos antes de integrarse en la organización y el resto eran conversos recientes (Armnstrong, 2015, p. 411). Muchos eran autodidactas. Y a esta situación se llega del camino de la propaganda, en donde la red ha jugado un papel esencial, pero también otros medios.

Para el público francés, existe la revista Dar al Islam en cuya portada del número 2 se puede leer sobre una foto de la Torre Eiffel el titular "Alá maldiga Francia". Pero su gran medio ha sido Internet. De hecho, ya se habla de guerras de cuarta generación, que son aquellas organizadas en torno a pequeños conflictos contra un enemigo que aparece y desaparece (Ranstorp en Reinares, Elorza, 2004, p. 205). Por Internet Al-Qaeda ha distribuido su Enciclopedia de la Yihad, en el que se recomendaba el uso de móviles adquiridos con nombre falso y el uso de Internet en lugares públicos y cibercafés en lugar del propio domicilio o a través del propio móvil.

También Internet se usa para el envío de virus masivos con el fin de causar pérdidas económicas a determinadas empresas norteamericanas y europeas que suponen un sobrecoste de protección informática, aunque la estrategia de Al-Qaeda e ISIS es la búsqueda de objetivos simbólicos, de gran resonancia mediática. Por ello, en 2014, durante el campeonato del mundo de futbol de Brasil, los hackers de ISIS lograron controlar diversos hashtags de la organización del torneo.

La propaganda más efectiva y que mayor repercusión ha alcanzado ha sido la fundamentada en la inserción de vídeos en Internet. Su inserción en los telediarios y en Internet plantea de nuevo la problemática de esa simbiosis entre terrorismo y medios de comunicación que se ha dado a lo largo de la historia y propicia un notable incremento de las adhesiones. En realidad, el Daesh no se ha inventado nada, ya que Al-Qaeda lo había puesto en práctica con anterioridad. Grupos como Septiembre Negro en los setenta o las Brigadas Rojas hicieron circular vídeos sobre el secuestro de la delegación israelí en los Juegos Olímpicos de 1972 o sobre el asesinato y secuestro de Roberto Peci en 1981. Ya en 2002 la policía española había localizado vídeos en los que se presenciaban escenas de ataques y emboscadas al ejército ruso en Chechenia junto a escenas de adiestramiento de terroristas en Indonesia (Domínguez en Veres, Abril, 2008, p. 84). La finalidad de estos vídeos era la conexión de la periferia de la organización con el centro por medio de la información y la epicidad de las glorias narradas. También estos vídeos servían para el sostenimiento de la moral en la lucha contra el enemigo y para enaltecer la batalla. Era vídeos que reproducían su gloria y que significaban también una prueba del delito. El reconocimiento de los hechos alcanzaba una significación dual para la posteridad. 
Hasta hace pocos años, los vídeos confeccionados por ISIS alertaban sobre los males de la contaminación y decadencia de Occidente y la necesidad de volver sobre los valores auténticos originarios del islam, en donde se encuentra el renacer del Califato, gracias a la personalidad del Califa, delegado del profeta en la tierra: Abu Bakr al-Baghdadi, muerto en junio de 2017. De ese modo la Red permite tanto atemorizar al enemigo como proporcionar su propia visión del mundo, con el fin de ganar adeptos, algo que se viene haciendo en los últimos años por todo el Magreb (Torres el Mar, 2016).

Con este fin, tanto Al-Qaeda como el ISIS tienen su propio aparato mediático: Al SAHAB para Al-Qaeda y Al Furqan y Al Hayat para el ISIS que funcionaron con la colaboración de Adam Yahiye Gadahn, un converso nacido en Oregón responsable de los vídeos de Bin Laden. Educado en Estados Unidos es conocedor de las técnicas de montaje y el diseño por ordenador, así como de técnicas de Chroma, según las cuales cualquier imagen se puede colocar sobre el fondo deseado. Este colaborador de Bin Laden será el autor del famoso vídeo, según el cual se pensaba que el líder de Al-Qaeda estaba escondido en las montañas de Afganistán y que ha dado lugar al icono más difundido de Bin Laden y por el cual será recordada su imagen. En 2015 fue abatido por un dron nortamericano en Pakistán.

En Internet también se vuelcan vídeos propagandísticos de la organización. Al-Qaeda fue la pionera en colocar imágenes de ataques en Afganistán contra comboyes del ejército norteamericano. A estos vídeos le siguieron los vídeos de ejecuciones y decapitaciones, como la del periodista Daniel Pearl o el empresario Nick Berg, en Iraq, en mayo de 2004, a manos de Abu Musab al-Zarqawi, vídeo que suscitó numerosas dudas por las similitudes del lugar de la ejecución con la cárcel de Abu Ghraib y el parecido del uniforme de la víctima con los utilizados en Guantánamo, detalle habitual en la mayoría de los vídeos posteriores.

En 2012 se colgó en Internet el vídeo del asesinato de James Foley, cronista de guerra en Libia, que había sido secuestrado un año antes durante 44 días. Tras pedir un tremendo rescate a la familia y a la agencia norteamericana Global Post, para la cual trabajaba, ISIS decidió acabar con su vida. El vídeo marcó una especie de paradigma fílmico para estos cruentos hechos: un sujeto arrodillado, vestido con mono naranja similar a los de Guantánamo, que aparentemente se ha arrepentido de sus pecados y que muestra serenidad ante la muerte que adivina cercana. A continuación un individuo enmascarado, de nacionalidad norteamericana, conocido posteriormente como el yihadista John, acusa de la responsabilidad de lo que le va a suceder a Estados y Unidos y Occidente a manos del Islam. Después viene el degollamiento. De manera similar murieron los periodistas Steven Sotloff y Jkenjo Goto, el cooperante David Haines y el conductor Alan Henning (Ortiz Moyano, 2015).

La fórmula se perfeccionó en cuanto a su capacidad de producir horror y su capacidad comunicativa para hacerse memorable. En febrero de 2015, 21 cristianos 
coptos fueron ejecutados de un tiro en la nuca mientras los planos se combinan con las imágenes del agua del mar que tan sólo está a unos metros. En marzo de 2015 se colgó un vídeo en el que aparecía el piloto jordano hecho prisionero Muath al Kaseasbeh. Tras una introducción, en la que repudiaba al rey Abdullah II de Jordania, reconocía y ofrecía detalles sobre las operaciones aéreas y las maniobras militares que los jordanos realizaban sobre Siria. A continuación, se mostraba su asesinato llevado a cabo con una crueldad extrema. Un muyahidín con una antorcha en la mano encendía un reguero de gasolina que, al inflamarse, se dirige de camino a una jaula, en donde estaba encerrado el piloto jordano. La escena es atroz: el piloto se abrasa hasta quedar carbonizado y la cámara recoge todos los detalles de la escena, incluso se recrea en el plano mediante el zoom de aproximación para retratar su cuerpo ennegrecido.

Todas estas imágenes han sufrido una gran evolución. De vídeos en donde primaba la frontalidad y en donde el protagonista hablaba de cara a la cámara se ha pasado a variaciones de ángulo, perspectivas en diagonal en busca de profundidad de campo con el fin de proporcionar mayor realismo y verosimilitud. Hasta hace unos pocos años los vídeos aparecían hablados solamente en árabe, mientras que en la actualidad aparecen subtitulados con el fin de captar a ciudadanos europeos. Muchos de ellos consiguieron ser eliminados de la Red, aunque muchos se pueden seguir encontrando hoy. Ejemplo de ello son los vídeos de Omar Omsen volcados en You Tube. Estos vídeos versan sobre temas diversos: desde el origen del universo según el Corán a la muerte de Bin Laden. En ellos se combinan imágenes de películas de Hollywood con testimonios de voluntarios, en los que se acusa a Occidente de los ataques al Islam, junto a testimonios de ISIS, inteligentemente sesgados, en los que se habla del big-bang y la necesidad de una causa inicial para explicar el origen del universo. En esta serie de vídeos, recogida bajo el epígrafe 19HH, Omse se muestra como el maestro de la Yihad 2.0., realizando una dura crítica a la cultura occidental, especialmente a la política francesa en contra del islamismo. En él aparecen imágenes de detenciones, allanamientos, testimonios de ciudadanos acusados falsamente, debates televisivos en donde se injuria al Islam, declaraciones del Ministro de Interior francés Manuel Valls, y, además, se presentan manifestaciones de racismo contra los árabes residentes en Francia ${ }^{3}$. Nada de la barbarie y las atrocidades cometidas por Al-Qaeda o el ISIS. En esta reresentación se deduce que el Islam es maravilloso y Occidente es la suma de todos los males terrenales fruto de la corrupción del hombre que no cree en Alá. Todo ello hilado con un montaje, propio del documental, en donde los contrastes señalan las contradicciones de Occidente, sabiamente manipuladas para conducirlas a la con-

3 https://archive.org/details/19HHRETOURAUXORIGINES. Consultado el 20 de enero de 2015. 
clusión deseada, en donde la Yihad es la única respuesta a los ataques que sufre el Islam. Los vídeos muestran realidades sensibles, capaces de persuadir a jóvenes marginales de los barrios periféricos que han sufrido el rechazo en sus carnes y se sienten limitados y marginados en la escuela, los centros de ocio frente a la autoridad política en medio de un horizonte de paro y hogares desestructurados sin una identidad cultural y social claramente definida. Uno de los testimonios apuntará tras su incorporación al ISIS: “¿Cómo se puede pensar renunciar a una vida así y aceptar regresar para vivir como un animal en Francia?" (Guolo, 2015, p. 134). Y el vídeo muestra a Obama sentado junto a Netanyahu para delatar la alianza tácita entre Israel y Estados Unidos. Un plano del Word Trade Center lanzando una columna de humo se contrapone a numerosos planos de soldados norteamericanos batallando en Iraq y Afganistán. Y frente a estas realidades, se muestra la placidez de un Islam pacífico, instructivo para los que lo siguen, en donde reina la calma de un sujeto que lee el Corán recostado sobre una piedra como signo de meditación. El vídeo avanza enseñando masas de musulmanes y túnicas blancas que se dirigen a la oración, a la verdad mientras la voz en off anuncia: "frente a la confusión actual la reacción a la objeción".

Estos vídeos ponen de relieve la acelerada evolución que, técnicamente, ha sufrido la propaganda islamista, sobre todo destaca el uso de la alta definición, el tratamiento del color, el uso del zoom, aceleraciones, ralentizaciones, fundidos, variaciones de encuadre, el montaje asociativo, el registro sonoro, la adecuación de la banda musical, el etalonaje o la igualación de luz entre plano y plano, etc. Hace tan sólo una década los vídeos de Al-Qaeda aparecían fuertemente pixelados, con imágenes borrosas y encuadres que manifestaban el temblor de la persona que filmaba, forzando el plano con un zoom de aproximación que delataba la distancia de la cámara respecto al objeto filmado.

Recientemente, en septiembre de 2014, el Estado Islámico confeccionó un documental titulado Flames of War. Se trata de un documental que combina imágenes de atentados con imágenes de la vida cotidiana, escenas de combate con operaciones de martirio, decapitaciones con entrevistas a militantes, todo bajo el sonido de un canto de guerra, el nasheed. El documental trata de destacar las posibles mentiras a las que Occidente somete a sus ciudadanos en materia de guerra al Islam.

Es más ISIS ha confeccionado programas infantiles, procedentes de occidente, como los dibujos animados de la serie Pepa Pi o Dora la Exploradora, a los cuales se les colocan diálogos acordes con la propaganda islamista con el fin de fabricar las mentes de los yihadistas del futuro. $\mathrm{Y}$ todo con un perfeccionamiento formal que resultaba impensable hace una década. Las guerras, como señala Alejandro Pizarroso se ejercen en el campo de batalla, pero también los medios de comunicación. Por ello no es de extrañar que ISIS haya confeccionado su propia serie de televisión. Igual que el American Way of Life se propagaba en los años cincuenta en 
Estados Unidos mediante series como Lucie Ball o Embrujada, el modo de vida estilo ISIS se propaga y difunde mediante el serial Prestadme vuestros oídos, título que hace referencia al comienzo del discurso de Marco Antonio en el drama de Shakespeare Julio César (Guolo, 2015, pp. 48-49). La serie está protagonizada por el periodista John Cantlie secuestrado por segunda vez en noviembre de 2012 junto al asesinado James Folley que ejerce el papel de narrador por las ruinas de Alepo para relatar cómo es la vida en el Califato en contra de la visión de los medios de comunicación de Occidente. Sinclair Lewis en su novela Babitt dijo en algún pasaje: "Gracias al cine, el mundo se americaniza" (Lewis). Hoy diríamos: gracias al vídeo, el mundo se islamiza.

\section{Conclusión: imágenes celebratorias, imágenes acusatorias.}

La filmación de sus propios crímenes utilizados en forma de amenaza a Occidente es el lado más visible de estas imágenes. En 1935, Leni Riefenstahl finalizó la filmación de una joya del cine documental, El triunfo de la voluntad que era un recordatorio de lo que había sido el congreso del partido nazi en Núremberg en 1934. La película tenía la finalidad de advertir a las potencias europeas y a los Estados Unidos del potencial humano y militar que poseía Alemania. Y lo mismo se da con estos vídeos Son imágenes amenazantes, pero a la vez no dejan de ser acusatorias (Sánchez-Biosca, 2006). De hecho, las imágenes de El triunfo de la voluntad se utilizaron como prueba contra Riefenstahl en el proceso de Núremberg contra los altos mandos nazis. Lo mismo sucedió con el registro de las matanzas realizadas en el campo de concentración croata de Jasenovak que supusieron base de la acusación contra sus responsables (Barnouw, 2005, p. 31). A la vez los dos ejemplos son paradigmáticos para poner de relieve que hemos construido muchos flecos de nuestra memoria sobre estos hechos con imágenes (Sánchez-Biosca, 2006:14) y esa imagen que tiene carácter de verdad, a pesar de su afán propagandístico, actúa, como señalaba Matuszewski, para callar la boca del mentiroso. Su carácter testimonial activa significación, mediante su presencia parcial o total en los medios, pero a la vez anula otros sentidos que dejan de formar parte de nuestro recuerdo. Y esta bifurcación del sentido favorece una memoria de los acontecimientos diversa a la visión del mundo que se tiene desde Occidente. No hay que olvidar que asistimos a un mundo en donde tres cuartas partes del planeta aplaudió los atentados del 11 de septiembre en un gesto de venganza antiestadounidense. Los vídeos y las imágenes son interpretados de una manera distinta en cada uno de esos dos mundos que constituyen el choque de civilizaciones entre el Islam y Occidente. Porque, para el público occidental, estos vídeos anulan mucha de la barbarie ejecutada contra el Islam al trasformar el Islam en una de sus vertientes que elimina a las restantes, la más radical y la que más se hace visible en los últimos años y que, por tanto, debe ser objeto de la venganza occidental, es 
más, facilita esa actitud vindicativa, mientras que, para los islamistas y muchos seguidores del Islam, esos vídeos suponen la reivindicación de una lucha legítima de luchadores por la libertad que se suma a las atrocidades realizadas en el terreno de la religión y la política desde la declaración del estado de Israel en 1948. Como señala Karem Armstrong, los videos encontrados a los terroristas del islamismo, entre los que se encuentran las amenazas de Bin Laden, acentúan esas injusticias como justificación de sus actos:

“En su declaración de guerra explotó la cultura de la reivindicación que se había gestado en el mundo musulmán, insistiendo en que durante siglos el pueblo del islam ha sufrido la agresión, la iniquidad y la injusticia impuestos por la alianza de cruzados y sionistas. En los vídeos de propaganda de Al-Qaeda este mensaje verbal se trasmite sobre un collage de dolor que muestra a niños palestinos hostigados por soldados israelíes; montones de cadáveres en el Líbano, Bosnia o Chechenia; el tiroteo de un niño palestino en Gaza; casas bombardeadas y derribadas; y pacientes ciegos y amputados yaciendo inertes en camas de hospital. Una investigación centrada en los hombres reclutados por Al-Qaeda después de 1999 reveló que la mayoría de ellos estaban motivados por el deseo de aliviar este sufrimiento. No sabía exactamente cómo podía ayudar -dijo un prisionero saudí en Guantánamo-, pero fui para ayudar a la gente, no para combatir. Feisal al-Dukhayil, que no era un musulmán practicante, se sintió tan perturbado por un programa de televisión que reflejaba las duras condiciones de las mujeres y los niños chechenos que se alistó inmediatamente. Pese a la retórica antiamericana de Bin Laden, el odio a los Estados Unidos no era la principal preocupación entre los reclutas; esto parece haberse producido sólo durante su adoctrinamiento en los campos de Al-Qaeda en Pakistán, donde todos eran enviados, incluidos los que pretendían combatir en Chechenia." (Armastrong, 2015, p. 409)

Un ejemplo de olvido de todo lo sucedido en el pasado y que es condicionante religioso y político de lo que se da en el presente, es parte del cine de Hollywood, en donde, mediante films como Homeland Security (2004), World Trade Center (2006) o Caza al terrorista (2014) plantean un mundo maniqueo en donde la justicia y la verdad es ostentada únicamente por Estados Unidos. Como señala Hungtinton, pretender que la cultura occidental, a causa del derrumbe del bloque comunista, se imponga en todas las civilizaciones es inmoral, además de exigir una cuota notable de sacrificios y violencia (2005, p. 84). Pero este cine plantea esa premisa como algo indiscutible y hay qué pensar en la recepción de esas películas entre las élites islamizadas, en un mundo en donde Internet lleva todo a la totalidad del Planeta, en países como Arabia Saudí, Irak, Siria o Pakistán, cuyos resultados y consecuencias son imprevisibles, pero, en todo caso, diferentes a los de la recepción en Occidente. Parte de la cultura occidental se esta fraguando según el empuje de cierta fe mesiánica que acompaña a Estados Unidos a lo largo de su historia (Gray, 2008, p. 157; 
Felipe y Gómez, 20011, p. 24) y que ha forjado un lenguaje, también audiovisual, fundamentado en un régimen maniqueísta de buenos y malos:

“Los americanos han sido atraídos habitualmente hacia un lenguaje que es redentor, apocalíptico y expansivo. Los americanos han experimentado y articulado, desde hace mucho, una sensación de urgencia, de colgar al borde del edificio del gran cambio (...) Han caído fácilmente en el hábito maniqueo de dividir el mundo entre tinieblas y luz, Mal y Bien, pasado y futuro, Satán y Cristo. Se han visto a sí mismos como una fuerza progresiva, redentora, la guerra en als filas del ejército de Cristo." (Asad, 2008, p. 103).

Este fenómeno no se va a terminar con la reciente derrota del Estado islámico. El caldo de cultivo sigue ahí. Los activistas islamistas seguirán actuando como lobos solitarios. Los atentados en zonas turísticas y aeropuertos continuarán ya que las noticias se extenderán como rizomas ilimitados a través de televisiones de todos los países implicados y algunos otros que colaborarán en el eco de la repercusión del suceso. La programación televisiva seguirá siendo secuestrada como en los casos de Munich, 11-S, 11-M, Charlie Ebdo, Bruselas, Bataclán, Niza, Londres, Barcelona. Y no queda más remedio que entrar en el juego, ya que el silencio no es posible, pero si es posible no cometer los mismos errores del pasado y ser conscientes de que al otro lado hay otro sujeto que forja su memoria de manera diferente a la de nuestra civilización y que, dependiendo del resultado de esa modulación o de ese mensaje, el futuro quedará por escribir de un modo u otro.

\section{Bibliografía}

1. Asad, T. (2008). Sobre el terrorismo suicida, Barcelona, Laertes.

2. Armstrong, Karen (2015). Campos de sangre, La religión y la historia de la violencia, Barcelona, Paidós.

3. Beck, Ulrich (2002). La sociedad del riesgo global, Madrid, Siglo XXI.

4. Beck, Ulric (2003). Sobre el terrorismo y la guerra, Barcelona, Paidós.

5. Cardini, Franco (2002). Nosotros y el Islam. Historia de un malentendido, Barcelona, Crítica.

6. Cockburn, Patrick (2014). ISIS. El retorno de la yihad, Barcelona, Ariel.

7. Domínguez, Florencio (2008). "Islam/Europa y la batalla de la Información", en Veres, Luis y Abril Ruth (Coords), Entre la Cruz y la Media Luna, Discursos y problemas de Seguridad, Madrid, Ediciones de la Torre.

8. Felipe, Fernando de, y Gómez, Iván (2011). Ficciones colaterales. Las huellas del 11-S en las series made in USA, Barcelona, UOC.

9. Gray, J. (2008). Misa negra. La religión apocalíptica y la muerte de la utopía, Barcelona, Paidós.

10. Gunaratna, Rohan (2004). "La amenaza de Al-Qaeda tras los atentados de Madrid", en Reinares, Fernando y Elorza, Antonio, El nuevo terrorismo islamista, Madrid, Temas de Hoy. 
11. Guolo, Renzo (2015). L'ultima utopía. Gli Jihadisti europei, Milán, Guerini e Associati.

12. Hoffman, Bruce (2004). "La continua amenaza de Al-Qaeda y el futuro del terrorismo", en Reinares, Fernando y Elorza, Antonio, El nuevo terrorismo islamista, Madrid, Temas de Hoy, 2004.

13. Huntington, Samuel P. (2005). El choque de civilizaciones y la reconfiguración del orden mundial, Barcelona, Paidós.

14. Lewis; Sinclair, Babitt, Barcelona, Noguer, s/f.

15. Ortiz Moyano, Andrés (2015). Yihad. Cómo el estado islámico ha conquistado Internet y los medios de comunicación, Barcelona, UOC.

16. Ranstorp, Magnus (2004). “Al-Qaeda en el ciberespacio: desafíso del terrorismo en la era de la información", Reinares, Fernando y Elorza, Antonio, El nuevo terrorismo islamista, Madrid, Temas de Hoy.

17. Reinares, Fernando y Elorza, Antonio (2004). "Presentación", en El nuevo terrorismo islamista, Madrid, Temas de Hoy.

18. Reinares, Fernando (2003). Terrorismo global, Madrid, Taurus.

19. Reinares, Fernando (2004). "Al-Qaeda, neosalafistas magrebíes y 11-M: sobre el nuevo terrorismo islamista en España", en REINARES, Fernando y ELORZA, Antonio, El nuevo terrorismo islamista, Madrid, Temas de Hoy.

20. Roy, Oliver (1995). Genealogía del islamismo, Barcelona, Edicions Bellaterra.

21. Roy, Oliver (2004). "Euroislam. ¿La Yihad desde dentro?, REINARES, Fernando y ELORZA, Antonio, El nuevo terrorismo islamista, Madrid, Temas de Hoy.

22. Sageman, M. (2008). Leaders Jihad, Philadelphia, University of Pennsylvania Press.

23. Sánchez-Biosca, Vicente, Cine de historia, cine de memoria, Madrid, Cátedra, 2006.

24. Torres el Mar (2016). Manuel, "La lucha por liderar el yihadismo magrebí aumenta su amenaza sobre España", en Mosaico. Blog sobre Seguridad Internacional. http:// www.seguridadinternacional.es/blog.mosaico/?q=es/content/la-lucha-por-liderarel-yihadismo-magreb\%C3\%AD-aumenta-la-amenaza-sobre-espa\%C3\%B1

25. Žižek, Slavoj (2006), “Lo real del ciberespacio”, en Debats, Valencia, no95, 2006.

26. -https://archive.org/details/19HHRETOURAUXORIGINES. Consultado el 20 de enero de 2015.

27. Veres, Luis (2017). Los lenguajes del terrorismo. De ETA al ISIS, Valencia, Tirant lo Blanc. 